\author{
Bronisław Ceranka*, Matgorzata Graczyk ${ }^{* *}$
}

\title{
ON D-OPTIMAL CHEMICAL BALANCE WEIGHING DESIGNS
}

\begin{abstract}
The paper deals with the problem of determining the chemical balance weighing designs satisfying the criterion of D-optimality under assumption that the measurement errors are equally correlated and they have the same variances. The existence conditions and the form of the optimal design are given. Moreover, some construction methods of the design matrices based on the incidence matrices of the balanced incomplete block designs and ternary balanced block designs are presented. Any example of construction is given.
\end{abstract}

Key words: balanced incomplete block design, chemical balance weighing design, D-optimality, ternary balanced block design.

\section{INTRODUCTION}

Let us consider $\boldsymbol{\Phi}_{n \times p, m}(-1,0,1)$, the class of $n \times p$ matrices $\mathbf{X}=\left(x_{i j}\right)$, $m=\max \left\{m_{1}, m_{2}, \ldots, m_{p}\right\}, m_{j}=\sum_{i=1}^{n} x_{i j}^{2}, i=1,2, \ldots, n, \quad j=1,2, \ldots, p$. Any matrix $\mathbf{X} \in \boldsymbol{\Phi}_{n \times p, m}(-1,0,1)$ is called the design matrix of the chemical balance weighing design. Originally, the name chemical balance weighing design pertained to experiments connected with determining of unknown weights of objects by use of balance with two pans which is called chemical balance. Nowadays, such designs are applied in many branches of knowledge including economic survey, see Banerjee (1975), Ceranka and Graczyk (2014). Some aspects of the other applications of the chemical balance weighing designs are presented in Koukouvinos and Seberry (1997), Graczyk (2013), Katulska and Smaga (2013). Various problems related to the chemical balance weighing designs are presented in the literature. They are focused on the optimality criteria of such designs. The classical works here are Jacroux and Notz (1983), Koukouvinos

* Full Professor, Department of Mathematical and Statistical Methods, Poznań University of Life Sciences. Sciences.

${ }^{* *}$ Ph.D., Department of Mathematical and Statistical Methods, Poznań University of Life 
(1996). The second group of issues is concerned with the determining new methods of construction the design matrices satisfying optimality conditions. The best general reference here are Gail and Kiefer (1982), Ceranka and Graczyk (2010, 2012), Katulska and Smaga (2010).

For any matrix $\mathbf{X} \in \boldsymbol{\Phi}_{n \times p, m}(-1,0,1)$ we consider linear model

$$
\mathbf{y}=\mathbf{X w}+\mathbf{e}
$$

where $\mathbf{y}$ is an $n \times 1$ random vector of observed measurements. Moreover, $\mathbf{w}$ is a $p \times 1$ vector representing unknown measurements of objects and $\mathbf{e}$ is an $n \times 1$ vector of random errors. We shall make two standing assumptions on the maps under consideration. It is required that there are no systematic errors, i.e. $\mathrm{E}(\mathbf{e})=\mathbf{0}_{n}$ and the errors are equal non-negative correlated and they have the same variances, i.e. $\operatorname{Cov}(\mathbf{e})=\sigma^{2} \mathbf{G}$, where $\sigma>0$ is known parameter, $\mathbf{G}$ is the $n \times n$ symmetric positive definite diagonal matrix of known elements given in the form

$$
\mathbf{G}=g\left[(1-\rho) \mathbf{I}_{n}+\rho \mathbf{1}_{n} \mathbf{1}_{n}^{\prime}\right], \quad g>0,0 \leq \rho<1 .
$$

Here, $\mathbf{0}_{n}$ is vector of zeros, $\mathbf{I}_{n}$ denotes identity matrix of rank $n$ and $\mathbf{1}_{n}$ denotes $n \times 1$ vector with element 1 everywhere. From now on, we have been working under the assumption that the matrix $\mathbf{G}$ is given in the form (2), only. The inverse of matrix $\mathbf{G}$ is given by the following formula $\mathbf{G}^{-1}=\frac{1}{g(1-\rho)}\left[\mathbf{I}_{n}-\frac{\rho}{1+\rho(n-1)} \mathbf{1}_{n} \mathbf{1}_{n}^{\prime}\right]$.

For the estimation of the vector of unknown measurements of objects $\mathbf{w}$, we use the normal equation $\mathbf{X G}^{\prime} \mathbf{G}^{-1} \mathbf{X}=\mathbf{X}^{\prime} \mathbf{G}^{-1} \mathbf{y}$. Owing to the fact that $\mathbf{G}$ is known positive definite matrix, $\mathbf{X}^{\prime} \mathbf{G}^{-1} \mathbf{X}$ is nonsingular if and only if $\mathbf{X}$ is of full column rank. In the case $\mathbf{X}^{\prime} \mathbf{G}^{-1} \mathbf{X}$ is nonsingular, the generalized least squares estimator of $\mathbf{w}$ is given by $\hat{\mathbf{w}}=\left(\mathbf{X}^{\prime} \mathbf{G}^{-1} \mathbf{X}\right)^{-1} \mathbf{X}^{\prime} \mathbf{G}^{-1} \mathbf{y}$ and $\operatorname{Var}(\hat{\mathbf{w}})=\sigma^{2}\left(\mathbf{X}^{\prime} \mathbf{G}^{-1} \mathbf{X}\right)^{-1}$. The matrix $\mathbf{M}=\mathbf{X}^{\prime} \mathbf{G}^{-1} \mathbf{X}$ is called the information matrix of the design $\mathbf{X}$.

In many problems concerning weighing experiments the D-optimal designs are considered. The design $\mathbf{X}_{\mathrm{D}}$ is D-optimal in the class of the designs 
$\boldsymbol{\Psi} \subset \boldsymbol{\Phi}_{n \times p, m}(-1,0,1)$ if $\operatorname{det}\left(\mathbf{X}^{\prime} \mathbf{G}^{-1} \mathbf{X}\right)^{-1}=\min \left\{\operatorname{det} \mathbf{M}^{-1}: \mathbf{X} \in \boldsymbol{\Psi}\right\}$. It is known that $\operatorname{det} \mathbf{M}^{-1}$ is minimal if and only if $\operatorname{det} \mathbf{M}$ is maximal. The concept of D-optimality was considered in the books of Raghavarao (1971), Banerjee (1975), Shah and Sinha (1989). In the paper Jacroux et al. (1983) the idea of Doptimality is presented for the case $\mathbf{G}=\mathbf{I}_{n}$. For a recent account pertained to the D-optimal weighing designs in the class $\boldsymbol{\Xi}_{n \times p}(-1,1)$, we refer the reader to Masaro and Wong (2008), Katulska and Smaga (2013), where $\boldsymbol{\Xi}_{n \times p}(-1,1)$ is the set of all $n \times p$ matrices $\mathbf{X}=\left(x_{i j}\right)$ with elements equal to -1 , or 1 only.

The aim of this paper is to present new results related to the D-optimal chemical balance weighing designs for that the random errors are equally nonnegative correlated and they have equal variances. We give lower bound for the determinant of the inverse of the information matrix. Moreover, we construct the chemical balance weighing design for which the determinant of the inverse of information matrix attains the lower bound.

\section{D-OPTIMAL DESIGNS}

For $\mathbf{X}=\left[\mathbf{x}_{1}, \mathbf{x}_{2}, \ldots, \mathbf{x}_{p}\right] \in \boldsymbol{\Phi}_{n \times p, m}(-1,0,1)$ and the variance matrix of errors $\sigma^{2} \mathbf{G}$, from Section 1c.1(ii)(b) Rao (1973) we obtain

Lemma 1. For diagonal elements of the inverse of information matrix $\mathbf{M}$ the inequality

holds.

$$
M_{j j}^{-1}=\left(\mathbf{x}_{j}^{\prime} \mathbf{G}^{-1} \mathbf{x}_{j}\right)^{-1} \geq \frac{g(1-\rho)}{\mathbf{x}_{j}^{\prime} \mathbf{x}_{j}-\frac{\mathbf{x}_{j}^{\prime} \mathbf{1}_{n} \mathbf{1}_{n}^{\prime} \mathbf{x}_{j} \rho}{1+\rho(n-1)}}
$$

Now, we give the lower bound of $\operatorname{det} \mathbf{M}^{-1}$.

Theorem 1. For $\mathbf{X} \in \boldsymbol{\Phi}_{n \times p, m}(-1,0,1)$ with the variance matrix of errors $\sigma^{2} \mathbf{G}$, we have

$$
\operatorname{det} \mathbf{M}^{-1} \geq\left(\frac{g(1-\rho)}{m}\right)^{p}
$$

Proof. First, note that by the Hadamard's inequality, $\operatorname{det} \mathbf{M}^{-1}$ is greater or equal to the product of diagonal elements of the matrix $\mathbf{M}^{-1}$. So we have 
$\operatorname{det} \mathbf{M}^{-1} \geq \prod_{j=1}^{p} M_{j j}^{-1}=\prod_{j=1}^{p}\left(\mathbf{x}_{j}^{\prime} \mathbf{G}^{-1} \mathbf{x}_{j}\right)^{-1}$. The elements of $\mathbf{x}_{j}$ are equal to $-1,0,1$, only. So, accordingly to the Lemma 1 we obtain (4), what completes the proof.

Definition 1. Any chemical balance weighing design $\mathbf{X} \in \boldsymbol{\Phi}_{n \times p, m}(-1,0,1)$ with the variance matrix of errors $\sigma^{2} \mathbf{G}$ is said to be regular D-optimal if it fulfills the equality in (4), that is

$$
\operatorname{det} \mathbf{M}^{-1}=\left(\frac{g(1-\rho)}{m}\right)^{p}
$$

It is worth noting that the regular D-optimal design is D-optimal, whereas the inverse sentence is not always true.

Theorem 2. Any chemical balance weighing design $\mathbf{X} \in \boldsymbol{\Phi}_{n \times p, m}(-1,0,1)$ with the variance matrix of errors $\sigma^{2} \mathbf{G}$ is regular D-optimal if and only if

(i) $\mathbf{X}^{\prime} \mathbf{X}=m \mathbf{I}_{p}$ for $\rho=0$,

(ii) $\mathbf{X}^{\prime} \mathbf{X}=m \mathbf{I}_{p}$ and $\mathbf{X}^{\prime} \mathbf{1}_{n}=\mathbf{0}_{p}$ for $0<\rho<1$.

Proof. Let $\mathbf{X} \in \boldsymbol{\Phi}_{n \times p, m}(-1,0,1)$ be the design matrix of the chemical balance weighing design with the variance matrix of errors $\sigma^{2} \mathbf{G}$. Thus

(i) If $\mathbf{X}^{\prime} \mathbf{X}=m \mathbf{I}_{p}$ then $\mathbf{x}_{j}^{\prime} \mathbf{x}_{j^{\prime}}=0$ for $j \neq j^{\prime}, j, j^{\prime}=1,2, \ldots, p$. From this fact and from Lemma 1 it results that $\rho=0$. Hence the inverse of the information matrix of the design $\mathbf{X}$ is equal $g^{-1} \mathbf{I}_{p}$, so it's determinant satisfies the equality (5).

(ii) If $0<\rho<1$ and $\mathbf{x}_{j}^{\prime} \mathbf{1}_{n}=0, j=1,2, \ldots, p$, then by Lemma 1 we deduce that the inverse of the information matrix of the design $\mathbf{X}$ is equal to $g(1-\rho) m^{-1} \mathbf{I}_{p}$. Therefore, the equality in (5) is also true.

Accordingly, the design $\mathbf{X}$ is regular D-optimal for $0 \leq \rho<1$. Hence the Theorem.

Corollary 1. Let $0<\rho<1$. The necessary condition for the existence of the regular D-optimal chemical balance weighing design $\mathbf{X} \in \boldsymbol{\Phi}_{n \times p, m}(-1,0,1)$ with the variance matrix of errors $\sigma^{2} \mathbf{G}$ is $m \equiv 0(\bmod 2)$. 
Let us consider any $\rho_{t}, 0<\rho<1, t=1,2, \rho_{1} \neq \rho_{2}$. It is worth pointing out that the design $\mathbf{X} \in \boldsymbol{\Phi}_{n \times p, m}(-1,0,1)$ satisfying conditions $\quad \mathbf{X}^{\prime} \mathbf{X}=m \mathbf{I}_{p}$ and $\mathbf{X}^{\prime} \mathbf{1}_{n}=\mathbf{0}_{p}$ is regular D-optimal in the sense of attaining equality (5), for $\rho_{1}$ and for $\rho_{2}$. We wanted to bring out that the lower bound is not the same for different numbers of $\rho$. Such a design is called robust. For a detailed discussion of robustness optimal design we refer the reader to Masaro and Wong (2008). Moreover, for the case $0 \leq \rho<1$, from (5) we can be notice that $\operatorname{det} \mathbf{M}^{-1}$ is maximal if $\rho=0$. When $\rho \rightarrow 1$ then $\operatorname{det} \mathbf{M}^{-1} \rightarrow 0$.

\section{CONSTRUCTION OF REGULAR D-OPTIMAL DESIGNS}

Several methods of the construction of the regular D-optimal designs were given by Masaro and Wong (2008) and Katulska and Smaga (2013) in the class $\boldsymbol{\Xi}_{n \times p}(-1,1)$. In this section, we present a new construction method of the regular D-optimal chemical balance weighing design in the class $\boldsymbol{\Phi}_{n \times p, m}(-1,0,1)$. It is based on the incidence matrices of the balanced incomplete block designs and the ternary balanced block designs.

Let $\mathbf{X} \in \boldsymbol{\Phi}_{n \times p, m}(-1,0,1)$ be the design matrix of the chemical balance weighing design in the form

$$
\mathbf{X}=\left[\begin{array}{cc}
2 \mathbf{N}_{1}^{\prime}-\mathbf{1}_{b_{1}} \mathbf{1}_{v}^{\prime} \\
\mathbf{N}_{2}^{\prime}-\mathbf{1}_{b_{2}} \mathbf{1}_{v}^{\prime}
\end{array}\right],
$$

where $\mathbf{N}_{1}$ is the incidence matrix of the balanced incomplete block design with the parameters $v, b_{1}, r_{1}, k_{1}, \lambda_{1}$ (see Raghavarao and Padgett, 2005) and $\mathbf{N}_{2}$ is the incidence matrix of the ternary balanced block design with the parameters $v$, $b_{2}, r_{2}, k_{2}, \lambda_{2}, \rho_{12}, \rho_{22}$ (see Billington, 1984). For the design $\mathbf{X}$ in (6), $n=b_{1}+b_{2}, \quad p=v, \quad m=b_{1}+b_{2}-\rho_{12}$.

Let us note that any chemical balance weighing design $\mathbf{X} \in \boldsymbol{\Phi}_{n \times p, m}(-1,0,1)$ is nonsingular, if the matrix $\mathbf{X} \mathbf{X}$ is nonsingular. Therefore, we have the following Lemma. 
Lemma 2. Any chemical balance weighing design $\mathbf{X} \in \boldsymbol{\Phi}_{n \times p, m}(-1,0,1)$ in the form (6) with the variance matrix of errors $\sigma^{2} \mathbf{G}$ is nonsingular if and only if $2 k_{1} \neq k_{2}$ or $2 k_{1}=k_{2} \neq v$.

Proof. As the first step we observe that the matrix $\mathbf{X}^{\prime} \mathbf{G}^{-1} \mathbf{X}$ is nonsingular if and only if the matrix $\mathbf{X} \mathbf{X}$ is nonsingular, as $\mathbf{G}$ is positive definite matrix. For $\mathbf{X} \in \boldsymbol{\Phi}_{n \times p, m}(-1,0,1)$ given in (6), we have

$$
\mathbf{X}^{\prime} \mathbf{X}=\left(4\left(r_{1}-\lambda_{1}\right)+r_{2}+2 \rho_{22}-\lambda_{2}\right) \mathbf{I}_{v}+\left(b_{1}-4\left(r_{1}-\lambda_{1}\right)+b_{2}+\lambda_{2}-2 r_{2}\right) \mathbf{1}_{v} \mathbf{1}_{v}^{\prime} .
$$

Next, we obtain

$$
\operatorname{det}\left(\mathbf{X}^{\prime} \mathbf{X}\right)=\left(4\left(r_{1}-\lambda_{1}\right)+r_{2}+2 \rho_{22}-\lambda_{2}\right)^{v-1}\left(\frac{r_{1}}{k_{1}}\left(v-2 k_{1}\right)^{2}+\frac{r_{2}}{k_{2}}\left(v-k_{2}\right)^{2}\right) .
$$

It is evident that $4\left(r_{1}-\lambda_{1}\right)+r_{2}+2 \rho_{22}-\lambda_{2}>0$, hence $\operatorname{det}\left(\mathbf{X}^{\prime} \mathbf{X}\right) \neq 0$ if and only if $2 k_{1} \neq k_{2}$ or $2 k_{1}=k_{2} \neq v$. So the Lemma is proved.

From Theorem 2, we can see that the optimality conditions are dependent on the parameter $\rho$. This implies that the methods of construction of the design matrix $\mathbf{X} \in \boldsymbol{\Phi}_{n \times p, m}(-1,0,1)$ are dependent on $\rho$, either. Thus we obtain the following Theorem.

Theorem 3. Let $\rho=0$. Any nonsingular chemical balance weighing design $\mathbf{X} \in \boldsymbol{\Phi}_{n \times p, m}(-1,0,1)$ given by (6) with the variance matrix of errors $\sigma^{2} \mathbf{I}_{n}$ is regular D-optimal if and only if

$$
b_{1}-4\left(r_{1}-\lambda_{1}\right)+b_{2}+\lambda_{2}-2 r_{2}=0 .
$$

Proof. For the design matrix $\mathbf{X} \in \boldsymbol{\Phi}_{n \times p, m}(-1,0,1)$ in (6) we have (7). Based on Theorem 2, for $\rho=0, \mathbf{X}^{\prime} \mathbf{X}=m \mathbf{I}_{p}$ if and only if $b_{1}-4\left(r_{1}-\lambda_{1}\right)+b_{2}+\lambda_{2}-2 r_{2}=0$ and thereby we obtain the condition (8).

Corollary 2. Let $\rho=0$. If the design $\mathbf{X} \in \boldsymbol{\Phi}_{n \times p, m}(-1,0,1)$ is regular Doptimal then $\operatorname{det} \mathbf{M}^{-1}=\left(\frac{g}{b_{1}+b_{2}-\rho_{12}}\right)^{p}$. 
In the particular case, the equality (8) is true when $b_{1}=4\left(r_{1}-\lambda_{1}\right)$ and $b_{2}+\lambda_{2}-2 r_{2}=0$.

Corollary 3. Let $\rho=0$. Any nonsingular chemical balance weighing design $\mathbf{X} \in \boldsymbol{\Phi}_{n \times p, m}(-1,0,1)$ given in (6) with the variance matrix of errors $\sigma^{2} \mathbf{I}_{n}$ is regular D-optimal if

and

$$
b_{1}=4\left(r_{1}-\lambda_{1}\right)
$$

$$
b_{2}=2 r_{2}-\lambda_{2} \text {. }
$$

The balanced incomplete block design for which the condition (9) is satisfied belongs to the family A (see, Raghavarao, 1971). Based on the series of the balanced incomplete block designs given by Raghavarao and Padgett (2005) and the ternary balanced block designs given in Billington (1984), we formulate the following Theorem.

Theorem 4. Let $\rho=0$. If the parameters of the balanced incomplete block design and the ternary balanced block design are equal to

(i) $v=b_{1}=4 s^{2}, \quad r_{1}=k_{1}=s(2 s+1), \quad \lambda_{1}=s(s+1)$ and $v=4 s^{2}, \quad b_{2}=4 u s^{2}$, $r_{2}=u\left(4 s^{2}-t-1\right), \quad k_{2}=4 s^{2}-t-1, \quad \lambda_{2}=u\left(4 s^{2}-2(t+1)\right), \quad \rho_{12}=u\left(4 s^{2}-(t+1)^{2}\right)$, $\rho_{22}=0.5 u t(t+1)$, where if $t=1,2$ then $s=2,3, \ldots$ or if $t=3$ then $s=3,4, \ldots$,

(ii) $\quad v=4 s^{2}, \quad b_{1}=4 s q, \quad r_{1}=q(2 s-1), \quad k_{1}=s(2 s-1), \quad \lambda_{1}=q(s-1) \quad$ and $v=4 s^{2}, \quad b_{2}=4 u s^{2}, \quad r_{2}=u\left(2 s^{2}-t-1\right), \quad k_{2}=4 s^{2}-t-1, \quad \lambda_{2}=u\left(4 s^{2}-2(t+1)\right)$, $\rho_{12}=u\left(4 s^{2}-(t+1)^{2}\right), \quad \rho_{22}=0.5 u t(t+1), \quad$ where $q \geq s$ and if $t=1,2$ then $s, q=2,3, \ldots$ or if $t=3$ then $s, q=3,4, \ldots$,

(iii) $v=(2 s+1)^{2}, b_{1}=4 q(2 s+1), r_{1}=4 q s, k_{1}=s(2 s+1), \lambda_{1}=q(2 s-1)$ and $v=(2 s+1)^{2}, \quad b_{2}=u(2 s+1)^{2}, \quad r_{2}=u\left(4 s^{2}+4 s-t\right), \quad k_{2}=4 s^{2}+4 s-t$, $\lambda_{2}=u\left(4 s^{2}+4 s-(2 t+1)\right), \quad \rho_{12}=u\left(4 s^{2}+4 s+1-(t+1)^{2}\right), \quad \rho_{22}=0.5 u t(t+1)$, where $4 q \geq 2 s+1$, and if $t=1$ then $s, q=1,2, \ldots$ or if $t=2,3$ then $s, q=2,3, \ldots$, $u=1,2, \ldots$, then the chemical balance weighing design $\mathbf{X} \in \boldsymbol{\Phi}_{n \times p, m}(-1,0,1)$ given in (6) with the variance matrix of errors $\sigma^{2} \mathbf{I}_{n}$ is regular D-optimal.

Proof. It is immediate to check that the parameters given in (i)-(iii) satisfy (9) and (10). 
The equality (8) is also satisfied when $b_{1}-4\left(r_{1}-\lambda_{1}\right)=\alpha$ and $b_{2}+\lambda_{2}-2 r_{2}=-\alpha$. Hence

Theorem 5. Let $\rho=0$. If the parameters of the balanced incomplete block design and the ternary balanced block design are equal to

(i) $v=5, \quad b_{1}=10, \quad r_{1}=4, \quad k_{1}=2, \quad \lambda_{1}=1 \quad$ and $\quad v=5, \quad b_{2}=5(s+4)$, $r_{2}=3(s+4), k_{2}=3, \lambda_{2}=s+6, \rho_{12}=s+12, \rho_{22}=s, s=1,2, \ldots$,

(ii) $v=7, b_{1}=42, r_{1}=12, k_{1}=2, \lambda_{1}=2$ and $v=k_{2}=7, b_{2}=r_{2}=s+13$, $\lambda_{2}=s+11, \quad \rho_{12}=s+1, \quad \rho_{22}=6, s=1,2, \ldots$,

(iii) $v=b_{1}=11, r_{1}=k_{1}=5, \lambda_{1}=2$ and $v=b_{2}=11, r_{2}=k_{2}=7, \lambda_{2}=4$, $\rho_{12}=5, \rho_{22}=1$,

(iv) $v=12, b_{1}=33, r_{1}=11, k_{1}=4, \lambda_{1}=3$ and $v=12, b_{2}=18, r_{2}=15$, $k_{2}=10, \lambda_{2}=11, \rho_{12}=1, \rho_{22}=7$,

(v) $v=b_{1}=15, \quad r_{1}=k_{1}=7, \lambda_{1}=3$ and $v=15, b_{2}=3(s+4), r_{2}=2(s+4)$, $k_{2}=10, \lambda_{2}=s+5, \rho_{12}=6-2 s, \rho_{22}=2 s+1, s=1,2$,

then the chemical balance weighing design $\mathbf{X} \in \boldsymbol{\Phi}_{n \times p, m}(-1,0,1)$ given in (6) with the variance matrix of errors $\sigma^{2} \mathbf{I}_{n}$ is regular D-optimal.

Proof. It is a simple manner to prove that the parameters given in (i)-(v) satisfy (8).

In particular case $r_{1}=\lambda_{1}$, the condition (8) is equal

$$
b_{1}+b_{2}=2 r_{2}-\lambda_{2}
$$

and we have Corollary.

Corollary 4. Let $\rho=0$. If ternary balanced block design with the parameters $v, b_{2}, r_{2}, k_{2}, \lambda_{2}, \rho_{12}, \rho_{22}$ for which $b_{2}<2 r_{2}-\lambda_{2}$ exists then $\mathbf{X} \in \boldsymbol{\Phi}_{n \times p, m}(-1,0,1)$ of the form

$$
\mathbf{X}=\left[\begin{array}{c}
\mathbf{1}_{b_{1}} \mathbf{1}_{v}^{\prime} \\
\mathbf{N}_{2}^{\prime}-\mathbf{1}_{b_{2}} \mathbf{1}_{v}^{\prime}
\end{array}\right] \text {, where } b_{1}=2 r_{2}-\lambda_{2}-b_{2}
$$

with the variance matrix of errors $\sigma^{2} \mathbf{I}_{n}$ is regular D-optimal.

Theorem 6. Let $\rho=0$. If the parameters of the ternary balanced block design are equal to 
(i) $\quad v=k_{2}=2 s, \quad b_{2}=r_{2}=4 s+u-2, \quad \lambda_{2}=4 s+u-4, \quad \rho_{12}=u$, $\rho_{22}=2 s-1, s=2,3, \ldots$,

(ii) $v=k_{2}=2 s+1, \quad b_{2}=r_{2}=4 s+u+1, \lambda_{2}=4 s+u-1, \rho_{12}=u, \rho_{22}=2 s$, $s=2,3, \ldots$,

(iii) $v=k_{2}=s, b_{2}=r_{2}=s+u-1, \lambda_{2}=s+u-2, \rho_{12}=u, \rho_{22}=0.5(s-1)$, $s=5,9,11,15$,

(iv) $v=5, \quad b_{2}=5(s+1), \quad r_{2}=4(s+1), \quad k_{2}=4, \quad \lambda_{2}=3 s+2, \quad \rho_{12}=4 s$, $\rho_{22}=2, s=1,2, \ldots$,

(v) $v=12, b_{2}=18, r_{2}=15, k_{2}=10, \lambda_{2}=11, \rho_{12}=1, \rho_{22}=7$,

$u=1,2, \ldots$, then the chemical balance weighing design $\mathbf{X} \in \boldsymbol{\Phi}_{n \times p, m}(-1,0,1)$ given in (12) with the variance matrix of errors $\sigma^{2} \mathbf{I}_{n}$ is regular D-optimal.

Proof. For $b_{1}=2 r_{2}-\lambda_{2}-b_{2}$, a trivial verification shows that the parameters given in (i)-(v) satisfy the condition (11).

In particular case $2 r_{2}=\lambda_{2}$, the condition (8) is equal

$$
b_{1}+b_{2}=4\left(r_{1}-\lambda_{1}\right)
$$

and we obtain the following Corollary.

Corollary 5. Let $\rho=0$. If balanced incomplete block design with the parameters $v, \quad b_{1}, \quad r_{1}, \quad k_{1}, \quad \lambda_{1}$ for which $b_{1}<4\left(r_{1}-\lambda_{1}\right)$ exists then $\mathbf{X} \in \boldsymbol{\Phi}_{n \times p, m}(-1,0,1)$ of the form

$$
\mathbf{X}=\left[\begin{array}{c}
2 \mathbf{N}_{1}^{\prime}-\mathbf{1}_{b_{1}} \mathbf{1}_{v}^{\prime} \\
\mathbf{1}_{b_{2}} \mathbf{1}_{v}^{\prime}
\end{array}\right], \text { where } b_{2}=4\left(r_{1}-\lambda_{1}\right)-b_{1}
$$

with the variance matrix of errors $\sigma^{2} \mathbf{I}_{n}$ is regular D-optimal.

Theorem 7. Let $\rho=0$. If the parameters of the balanced incomplete block design are equal to

(i) $v=4 s+1, b_{1}=2(4 s+1), r_{1}=4 s, k_{1}=2 s, \lambda_{1}=2 s-1$,

(ii) $v=4(s+1), b_{1}=2(4 s+3), r_{1}=4 s+3, k_{1}=2(s+1), \lambda_{1}=2 s+1$,

(iii) $v=b_{1}=4 s^{2}-1, r_{1}=k_{1}=2 s^{2}-1, \lambda_{1}=s^{2}-1$,

(iv) $v=b_{1}=4 s+3, r_{1}=k_{1}=2 s+1, \lambda_{1}=s$,

(v) $v=b_{1}=4 s+7, \quad r_{1}=k_{1}=4 s+3, \quad \lambda_{1}=2 s+1$, 
where $4 s+1$ and $4 s+3$ is a prime or a prime power, $s=1,2, \ldots$, then the chemical balance weighing design $\mathbf{X} \in \boldsymbol{\Phi}_{n \times p, m}(-1,0,1)$ given in (14) with the variance matrix of errors $\sigma^{2} \mathbf{I}_{n}$ is regular D-optimal.

Proof. For $b_{2}=4\left(r_{1}-\lambda_{1}\right)-b_{1}$, obviously, the parameters given in (i)-(v) satisfy the equality (13).

Now, we consider the case $0<\rho<1$.

Theorem 8. Let $0<\rho<1$. Any nonsingular chemical balance weighing design $\mathbf{X} \in \boldsymbol{\Phi}_{n \times p, m}(-1,0,1)$ given in (6) with the variance matrix of errors $\sigma^{2} \mathbf{G}$ is regular D-optimal if and only if the condition (8) is satisfied and

$$
b_{1}-2 r_{1}+b_{2}-r_{2}=0 \text {. }
$$

Proof. For $0<\rho<1$, according to the Theorem 2, the design $\mathbf{X} \in \boldsymbol{\Phi}_{n \times p, m}(-1,0,1)$ in (6) is regular D-optimal if and only if the conditions $\mathbf{X}^{\prime} \mathbf{X}=m \mathbf{I}_{p}$ and $\mathbf{X}^{\prime} \mathbf{1}_{n}=\mathbf{0}_{p}$ are fulfilled. As in the proof of the Theorem 3, the condition $\mathbf{X}^{\prime} \mathbf{X}=m \mathbf{I}_{p}$ is satisfied if and only if the equality (8) holds. Moreover, for $0<\rho<1$, the matrix $\mathbf{X} \in \mathbf{\Phi}_{n \times p, m}(-1,0,1)$ in (6) satisfies the condition $\mathbf{X}^{\prime} \mathbf{1}_{n}=\mathbf{0}_{p}$. So, the Theorem is proved.

Theorem 9. Let $0<\rho<1$. If the parameters of the balanced incomplete block design and ternary balanced block design are equal to

(i) $\quad v=4 s+1, \quad b_{1}=2(4 s+1), \quad r_{1}=4 s, \quad k_{1}=2 s, \quad \lambda_{1}=2 s-1 \quad$ and $v=b_{2}=4 s+1, r_{2}=k_{2}=4 s+3, \lambda_{2}=4 s+5, \quad \rho_{12}=4 s-3, \rho_{22}=3, s=2,3, \ldots$,

(ii) $v=4(s+1), \quad b_{1}=2(4 s+3), \quad r_{1}=4 s+3, \quad k_{1}=2(s+1), \quad \lambda_{1}=2 s+1 \quad$ and $v=k_{2}=4(s+1), \quad b_{2}=r_{2}=8 s+u+6, \quad \lambda_{2}=8 s+u+4, \quad \rho_{12}=u, \quad \rho_{22}=4 s+3$, $s, u=1,2, \ldots$,

(iii) $v=b_{1}=4 s^{2}, \quad r_{1}=k_{1}=s(2 s+1), \quad \lambda_{1}=s(s+1)$ and $v=4 s^{2}, \quad b_{2}=4 s^{3}$, $r_{2}=2 s\left(2 s^{2}-1\right), k_{2}=2\left(2 s^{2}-1\right), \lambda_{2}=\rho_{12}=4 s\left(s^{2}-1\right), \rho_{22}=s, s=2,3, \ldots$,

(iv) $v=b_{1}=16 s^{2}, \quad r_{1}=k_{1}=2 s(4 s+1), \quad \lambda_{1}=2 s(2 s+1) \quad$ and $\quad v=16 s^{2}$, $b_{2}=16 s^{3}, \quad r_{2}=4 s\left(4 s^{2}-1\right), \quad k_{2}=4\left(4 s^{2}-1\right), \quad \lambda_{2}=8 s\left(2 s^{2}-1\right), \quad \rho_{12}=16 s\left(s^{2}-1\right)$, $\rho_{22}=6 s, s=2,3, \ldots$, 
(v) $v=b_{1}=36 s^{2}, \quad r_{1}=k_{1}=3 s(6 s+1), \quad \lambda_{1}=3 s(3 s+1) \quad$ and $\quad v=36 s^{2}$, $b_{2}=72 s^{3}, \quad r_{2}=6 s\left(12 s^{2}-1\right), \quad k_{2}=3\left(12 s^{2}-1\right), \quad \lambda_{2}=12 s\left(6 s^{2}-1\right)$, $\rho_{12}=18 s\left(4 s^{2}-1\right), \rho_{22}=6 s, s=1,2, \ldots$,

then the chemical balance weighing design $\mathbf{X} \in \boldsymbol{\Phi}_{n \times p, m}(-1,0,1)$ given by (6) with the variance matrix of errors $\sigma^{2} \mathbf{G}$ is regular D-optimal.

Proof. An easy computation shows that the parameters given in (i)-(v) satisfy conditions (8) and (15).

In particular case $b_{1}=r_{1}$, the condition (15) is equal

$$
b_{1}=b_{2}-r_{2}
$$

and we have Corollary.

Corollary 6. Let $0<\rho<1$. If ternary balanced block design with the parameters $v, b_{2}, r_{2}, k_{2}, \lambda_{2}, \rho_{12}, \rho_{22}$ for which $b_{2}>r_{2}$ exists, then $\mathbf{X} \in \boldsymbol{\Phi}_{n \times p, m}(-1,0,1)$ of the form (12) with the variance matrix of errors $\sigma^{2} \mathbf{G}$ is regular D-optimal, where $b_{1}=b_{2}-r_{2}$.

Theorem 10. Let $0<\rho<1$. If the ternary balanced block design are equal to

(i) $\quad v=5, \quad b_{2}=5(s+1), \quad r_{2}=4(s+1), \quad k_{2}=4, \quad \lambda_{2}=3 s+2, \quad \rho_{12}=4 s$, $\rho_{22}=2, s=1,2 \ldots$,

(ii) $v=12, b_{2}=18, r_{2}=15, k_{2}=10, \lambda_{2}=11, \rho_{12}=1, \rho_{22}=7$,

then the chemical balance weighing design $\mathbf{X} \in \boldsymbol{\Phi}_{n \times p, m}(-1,0,1)$ given in (12) with the variance matrix of errors $\sigma^{2} \mathbf{G}$ is regular D-optimal.

Proof. For $b_{1}=2 r_{2}-\lambda_{2}-b_{2}$, of course the parameters given in (i) and (ii) satisfy the equality (16).

In particular case $2 b_{2}=r_{2}$, the condition (15) is equal

$$
b_{2}=b_{1}-2 r_{1}
$$

and we have Corollary.

Corollary 7. Let $0<\rho<1$. If balanced incomplete block design with the parameters $v, b_{1}, r_{1}, k_{1}, \lambda_{1}$ for which $b_{1}>2 r_{1}$ exists, then $\mathbf{X} \in \boldsymbol{\Phi}_{n \times p, m}(-1,0,1)$ 
of the form (12) with the variance matrix of errors $\sigma^{2} \mathbf{G}$ is regular D-optimal, where $b_{2}=b_{1}-2 r_{1}$.

Theorem 11. Let $0<\rho<1$. If the parameters of the balanced incomplete block design are equal to

(i) $v=4 s+1, b_{1}=2(4 s+1), r_{1}=4 s, k_{1}=2 s, \lambda_{1}=2 s-1$,

(ii) $v=b_{1}=4 s^{2}-1, r_{1}=k_{1}=2 s^{2}-1, \lambda_{1}=s^{2}-1$,

(iii) $v=b_{1}=4 s+3, r_{1}=k_{1}=2 s+1, \lambda_{1}=s$,

(iv) $v=b_{1}=8 s+7, r_{1}=k_{1}=4 s+3, \lambda_{1}=2 s+1$,

where $4 s+1$ and $4 s+3$ is a prime or a prime power, $s=1,2 \ldots$, then the chemical balance weighing design $\mathbf{X} \in \boldsymbol{\Phi}_{n \times p, m}(-1,0,1)$ given in (14) with the variance matrix of errors $\sigma^{2} \mathbf{G}$, is regular D-optimal.

Proof. For $b_{2}=4\left(r_{1}-\lambda_{1}\right)-b_{1}$, it is a simple matter to check that the parameters given in (i)-(iv) satisfy (17).

\section{EXAMPLE}

As an application of above theory let us consider the class $\boldsymbol{\Phi}_{12 \times 5,8}(-1,0,1)$. Based on the Theorem 10(i), let us consider the ternary balanced block design with the parameters $v=5, b_{2}=10, r_{2}=8, k_{2}=4, \lambda_{2}=5 \quad \rho_{12}=4, \quad \rho_{22}=2$ given by the incidence matrix $\mathbf{N}_{2}$, where

$$
\mathbf{N}_{2}=\left[\begin{array}{llllllllll}
0 & 1 & 1 & 2 & 0 & 0 & 2 & 1 & 0 & 1 \\
0 & 0 & 1 & 1 & 2 & 1 & 0 & 2 & 1 & 0 \\
2 & 0 & 0 & 1 & 1 & 0 & 1 & 0 & 2 & 1 \\
1 & 2 & 0 & 0 & 1 & 1 & 0 & 1 & 0 & 2 \\
1 & 1 & 2 & 0 & 0 & 2 & 1 & 0 & 1 & 0
\end{array}\right]
$$

Here, $b_{1}=2$. Therefore, we form the design matrix $\mathbf{X} \in \boldsymbol{\Phi}_{12 \times 5,8}(-1,0,1)$ of the regular D-optimal chemical balance weighing design in (12) as 


$$
\mathbf{X}^{\prime}=\left[\begin{array}{rrrrrrrrrrrr}
1 & 1 & -1 & 0 & 0 & 1 & -1 & -1 & 1 & 0 & -1 & 0 \\
1 & 1 & -1 & -1 & 0 & 0 & 1 & 0 & -1 & 1 & 0 & -1 \\
1 & 1 & 1 & -1 & -1 & 0 & 0 & -1 & 0 & -1 & 1 & 0 \\
1 & 1 & 0 & 1 & -1 & -1 & 0 & 0 & -1 & 0 & -1 & 1 \\
1 & 1 & 0 & 0 & 1 & -1 & -1 & 1 & 0 & -1 & 0 & -1
\end{array}\right] .
$$

\section{CONCLUSIONS}

Here, some problems related to D-optimality criterion are presented. These designs are considered under the assumption that the errors are correlated. The disruption in data or problems with accuracy of measurements influence the value of this correlation. It is not possible to determine a regular D-optimal chemical balance weighing design in any class $\mathbf{X} \in \boldsymbol{\Phi}_{n \times p}(-1,0,1)$. Therefore, in the literature new construction methods of D-optimal designs have been presented. The construction of such designs is based on the incidence matrices of some known block designs. It is worth emphasizing that presented construction extended the list of possible classes $\boldsymbol{\Phi}_{n \times p}(-1,0,1)$ in that regular D-optimal chemical balance weighing design exists. Moreover, the conditions determining optimal designs given in Theorem 2 allow to conduct the study on the properties of such designs.

\section{REFERENCES}

Banerjee K.S. (1975), Weighing Designs for Chemistry, Medicine, Economics, Operations Research, Statistics, Marcel Dekker Inc., New York.

Billington E.J. (1984), Balanced n-ary designs: a combinatorial survey and some new results, Ars Combin. 17 A, 133-144.

Ceranka B., Graczyk M. (2010), Notes about singular chemical balance weighing design, Acta Universitatis Lodziensis, Folia Oeconomica 235, 241-246.

Ceranka B., Graczyk M. (2012), Notes on the optimum chemical balance weighing design, Acta Universitatis Lodziensis, Folia Oeconomica 269, 91-101.

Ceranka B., Graczyk M. (2014), On certain A-optimal biased spring balance weighing designs, Statistics in Transition new series 15, 317-326.

Gail Z., Kiefer J. (1982), Construction methods for D-optimum weighing designs when $n \equiv 3 \bmod 4$, The Annals of Statistics $10,502-510$.

Graczyk M. (2013), Some applications on weighing designs, Biometrical Letters 50, 15-26.

Jacroux M., Notz W. (1983), On the optimality of spring balance weighing designs, The Annals of Statistics 11, 970-978.

Jacroux M., Wong C.S., Masaro J.C. (1983), On the optimality of chemical balance weighing design, Journal of Statistical Planning and Inference 8, 213-240. 
Katulska K., Smaga Ł. (2010), On some construction of D-optimal chemical balance weighing designs, Colloquium Biometricum 40, 155-164.

Katulska K., Smaga Ł. (2013), A note on D-optimal chemical balance weighing designs and their applications, Colloquium Biometricum 43, 37-45.

Koukouvinos Ch. (1996), Linear models and D-optimal designs for $n \equiv 2 \bmod 4$, Statistics and Probability Letters 26, 329-332.

Koukouvinos Ch., Seberry J. (1997), Weighing matrices and their applications, Journal of Statistical Planning and Inference 62, 91-101.

Masaro J., Wong C.S. (2008), Robustness of A-optimal designs, Linear Algebra and its Applications 429, 1392-1408.

Raghavarao D. (1971), Constructions and Combinatorial Problems in Design of Experiment, John Wiley and Sons. New York.

Raghavarao D., Padgett L.V. (2005), Block Designs, Analysis, Combinatorics and Applications, Series of Applied Mathematics 17, Word Scientific Publishing Co. Pte. Ltd. Singapore.

Rao C.R. (1973), Linear Statistical Inference and its Applications, John Wiley and Sons Inc. New York.

Shah K.R., Sinha B.K. (1989), Theory of Optimal Designs, Springer-Verlag, Berlin.

Bronisław Ceranka, Małgorzata Graczyk

\section{D-OPTYMALNE CHEMICZNE UKLADY WAGOWE O NIEUJEMNIE SKORELOWANYCH BLĘDACH: KONSTRUKCJA}

Streszczenie. W pracy przedstawiamy zagadnienie estymacji nieznanych miar $p$ obiektów $\mathrm{w}$ doświadczeniu przeprowadzonym zgodnie z modelem chemicznego układu wagowego przy założeniu, że nie ma błędów systematycznych, są one nieujemnie skorelowane i mają jednakowe wariancje.

Układ D-optymalny jest to układ, w którym wyznacznik odwrotności macierzy informacji jest minimalny. Podstawowy wynik pracy to rozszerzenie znanej z literatury klasy układów, w których można wyznaczyć układ regularnie D-optymalny. Podane zostało dolne ograniczenie śladu odwrotności macierzy informacji oraz warunki, przy spełnieniu których to dolne ograniczenie jest osiągnięte. Przedstawiono również nowe metody konstrukcji regularnego D-optymalnego chemicznego układu wagowego w oparciu o macierze incydencji układów zrównoważonych o blokach niekompletnych oraz trójkowych zrównoważonych układów bloków.

Słowa kluczowe: chemiczny układ wagowy, trójkowy zrównoważony układ bloków, układ D-optymalny, układ zrównoważony o blokach niekompletnych. 